\title{
Cytochrome P450 1A1 (CYP1A1) Inhibitor $\alpha$-Naphthoflavone Interferes with UDP-Glucuronosyltransferase (UGT) Activity in Intact but Not in Permeabilized Hepatic Microsomes from 3-Methylcholanthrene-Treated Rats: Possible Involvement of UGT-P450 Interactions
}

\author{
Ken-ichiro Taura, ${ }^{a}$ Eri Naito, ${ }^{a}$ Yuji IshiI,${ }^{a}$ Masa-aki Mori,${ }^{b}$ Kazuta Oguri, ${ }^{c}$ and Hideyuki YamadA $* a$ \\ ${ }^{a}$ Graduate School of Pharmaceutical Sciences, Kyushu University; ${ }^{b}$ Department of Health Sciences, School of Medicine, \\ Kyushu University; 3-1-1 Maidashi, Higashi-ku, Fukuoka 812-8582, Japan: and ${ }^{c}$ School of Pharmaceutical Sciences, \\ Kyushu University of Health and Welfare; 1714-1 Yoshino-machi, Nobeoka, Miyazaki 882-8508, Japan. \\ Received August 11, 2003; accepted September 30, 2003
}

The effects of cytochrome P450 (P450, CYP) ligands and permeabilization of microsomes on 3-hydroxybenzo(a)pyrene [3-OH-B(a)P] glucuronidation mediated by rat hepatic microsomes were studied. While the UDP-glucuronosyltransferase (UGT) activity with non-permeabilized microsomes from 3-methylcholanthrene (MC)-treated rats was markedly reduced by $\alpha$-naphthoflavone (NF), this inhibitor had hardly any effect when permeabilized microsomes were used in which the inhibitor was expected to have easy access to UGT. Kinetic analysis indicated that the inhibitory effect of $\alpha$-NF is competitive. These results suggest that a UGT isoform(s) involved in 3-OH-B(a)P glucuronidation is interfered by a CYP1A inhibitor via a mechanism dependent on the intact nature of microsomal membranes in MC-treated rats. It is likely that $\mathrm{P450}$ functions as a substrate transporter for some isoforms of UGT via possible interactions between UGT and P450.

Key words interaction; UDP-glucuronosyltransferase (UGT); cytochrome P450 (CYP); inhibitor; membrane topology

UDP-glucuronosyltransferase (UGT) contributes to the inactivation of a number of exogenous and endogenous compounds by conjugating them with glucuronic acid. ${ }^{1,2)}$ The UGT isoforms are separated into two families (UGT1 and UGT2), based on the sequence identities. ${ }^{3)}$ These UGTs show an overlapping but distinct substrate specificity, and are expressed in an organ-specific manner [see review of Tukey and Strassburg ${ }^{4}$ ]. Increasing evidence suggests that there is a change in the catalytic function of UGT produced by oligomer formation of UGT isoforms. ${ }^{5-7)}$ A recent study from this laboratory also revealed that glucuronidation of morphine at the 6-position by UGT2B21 expressed in COS cells is greatly enhanced by co-expression of a different isoform, UGT2B22. ${ }^{8}$ Thus, UGT function appears to be changed dynamically through protein-protein interactions.

UGT is anchored to the endoplasmic reticulum (ER) membrane by the transmembrane domain near the $\mathrm{C}$-terminal, and the main body of the enzyme, including the catalytic site, is believed to be present in the lumen of the ER. ${ }^{2,9,10)}$ This mode of topology causes latency, a diagnostic feature of UGT, whereby UGT activity is activated by disruption of the microsomal membrane with detergent. ${ }^{11)}$ On the other hand, Ikushiro et al. (1997) ${ }^{12)}$ have reported that formation of UGT hetero-oligomer facilitates the transport of UDP-glucuronic acid from the cytosol to the inside of the ER. This observation suggests that a putative UDP-glucuronic acid transporter, which is expressed in the membrane, is activated by UGT oligomer. If this is the case, UGT would be partially embedded in ER membrane so that it can interact with the transporter. In clear contrast to UGT, an entire molecule containing the functional domain of cytochrome P450 (P450, CYP), which is anchored by the N-terminal region to the ER, is present in cytosol. ${ }^{13-15)}$ It has, however, been reported that P450 is partially drawn into the lipid bilayer membrane to change its secondary structure and increase its catalytic activity. ${ }^{16)}$ It remains unclear whether functional interactions between P450 and UGT exist.

Our previous study provided direct evidence for possible interactions between CYP1A1 and other microsomal enzymes using affinity chromatography with a CYP1A1-conjugated column. ${ }^{17)}$ In that study, CYP1A1-UGTs and CYP1A1microsomal epoxide hydrolase $(\mathrm{mEH})$ interactions were suggested. Recently, we have demonstrated that $\mathrm{mEH}$ function is significantly enhanced by multiple forms of P450. ${ }^{18)}$ Thus, microsomal drug metabolizing enzymes can interact with each other so that they rapidly convert exogenous compounds to highly polar metabolites which are easily excreted. However, to the best of our knowledge, it has never before been proven that P450 modifies UGT function via a protein-protein interaction. Although the membrane topology of these enzymes is quite different, several forms of UGT were effectively trapped on a CYP1A1-conjugated column. ${ }^{17)}$ Thereby, it may be that there is functional co-operation between these enzymes.

In this study, we propose the hypothesis that P450 associates with UGT and functions not only as a producer but also as a transporter of the substrate needed by UGT. To investigate this possibility, we have examined the effects of P450 inhibitors and substrates on the hepatic microsomal activity of UGT. UGT activity was analyzed using 3-hydroxybenzo(a)pyrene [3-OH-B(a)P], which is a major metabolite of $\mathrm{B}(\mathrm{a}) \mathrm{P}$ produced by $\mathrm{P} 450 .{ }^{19,20)}$

\section{MATERALS AND METHODS}

Materials 3-OH-B(a)P was synthesized by the method previously reported ${ }^{21)}$ and 3-OH-B(a)P glucuronide [3-OGA$\mathrm{B}(\mathrm{a}) \mathrm{P}]$ was a gift from Dr. Kinoshita. ${ }^{22)} \alpha$ - and $\beta$-Naphthoflavone (NF) were purchased from Aldrich Chemical Co. Inc. (Milwaukee, WI, U.S.A.). Metyrapone was obtained from Sigma Chemical Co. (St. Louis, MO, U.S.A.). SKF525A was a gift from SmithKline \& French Laboratories 
(Philadelphia, PA, U.S.A.). All other reagents were of the highest quality commercially available.

Animals, Treatment and Preparation of Liver Microsomes Male Sprague-Dawley rats (body weight, 140$160 \mathrm{~g}$ ) were purchased from Charles River Japan Inc. (Yokohama, Japan). The rats were treated with 3-methylcholanthrene (MC, $20 \mathrm{mg} / \mathrm{kg} / 2 \mathrm{ml}$ corn oil, i.p.) for $4 \mathrm{~d}$. After the last dose, the animals were fasted overnight and the livers were removed. Preparation of hepatic microsomes was performed as described previously, ${ }^{23)}$ and the microsomal samples were stored at $-80^{\circ} \mathrm{C}$ before use. Unless otherwise stated, equal volumes of microsomal samples from four rats were mixed and used as the enzyme sources.

Determination of 3-OH-B(a)P Glucuronosyltransferase Activity The activity of 3-OH-B(a)P glucuronidation was assayed by the method of Bock and Lilienblum. ${ }^{11)}$ with minor modifications. The incubation mixture consisted of $5 \mu \mathrm{M} \mathrm{3-}$ OH-B(a)P, $3 \mathrm{~mm} \mathrm{MgCl}_{2}, 1 \mathrm{~mm}$ UDP-glucuronic acid and $50 \mu \mathrm{g}$ liver microsomal protein in a final volume of $500 \mu \mathrm{l}$ of $50 \mathrm{~mm}$ Tris- $\mathrm{HCl}$ (pH 7.4). In some cases, liver microsomes were permeabilized by treating them at $4{ }^{\circ} \mathrm{C}$ for $30 \mathrm{~min}$ with $0.01 \%$ (w/v, final concentration) Brij58, a nonionic detergent, prior to the assay. The incubation mixture was pre-heated at $37^{\circ} \mathrm{C}$ for $3 \mathrm{~min}$, and the reaction $(5 \mathrm{~min}$ ) was started by adding substrate. The incubation was stopped by adding $0.1 \mathrm{ml} 0.5 \mathrm{M}$ trichloroacetic acid followed by addition of $2 \mathrm{ml}$ methanol and an internal standard (o-hydroxybiphenyl, $25 \mu \mathrm{g})$. The mixture was centrifuged, and an aliquot $(50 \mu \mathrm{l})$ of the supernatant was subjected to HPLC. The HPLC conditions were as follows: column, Nova-Pak C18 $(0.8 \times 10 \mathrm{~cm}$, particle size, $4 \mu \mathrm{m}$, Waters Corp., Milford, MA, U.S.A.); mobile phase, solvent A $[50 \mathrm{~mm}$ ammonium acetate $(\mathrm{pH}$ $5.0)$-acetonitrile $=6.5: 3.5(\mathrm{v} / \mathrm{v})]$ for $5 \mathrm{~min}$ and a linear gradient from solvent $A$ to $70 \%(\mathrm{v} / \mathrm{v})$ solvent $\mathrm{B}$ in solvent $\mathrm{A}$ for $26 \mathrm{~min}$ [solvent $\mathrm{B}$, methanol/acetonitrile $=3 / 7,(\mathrm{v} / \mathrm{v})$ ]; flow rate, $1 \mathrm{ml} / \mathrm{min}$; and detection, fluorescence at $450 \mathrm{~nm}$ with excitation at $300 \mathrm{~nm}$. The retention time of 3-OGA-B(a)P and internal standard were 4.6 and $14.0 \mathrm{~min}$, respectively. The linearity of the calibration curve was confirmed over the range 0.04 to $4.0 \mathrm{nmol} / 500 \mu \mathrm{l}$ incubation mixture.

Other Methods Protein concentrations were determined by the method of Miller, ${ }^{24)}$ which is a modification of the Lowry method with bovine serum albumin as standard. ${ }^{25}$ ) The significance of differences was examined by analysis of variance (ANOVA), using STATview software (ver. J 4.02).

\section{RESULTS}

Glucuronidation of 3-OH-B(a)P in rats is catalyzed by several UGT isoforms including MC-inducible UGT1A7. 11,26,27) Therefore, we used liver microsomes from MC-treated rats in the initial stages of this study. When the effects of the classical P450 inhibitors $\alpha$-NF, SKF-525A and metyrapone on 3$\mathrm{OH}-\mathrm{B}(\mathrm{a}) \mathrm{P}$ glucuronidation were examined using non-permeabilized microsomes as the enzyme source, only $\alpha$-NF significantly reduced the activity (Fig. 1, panel A). On the other hand, the inhibitory effect of $\alpha$-NF was markedly reduced when microsomes were permeabilized by detergent (Fig. 1, panel B). Thus, $\alpha$-NF inhibited UGT activity more effectively under non-permeabilized than permeabilized conditions.

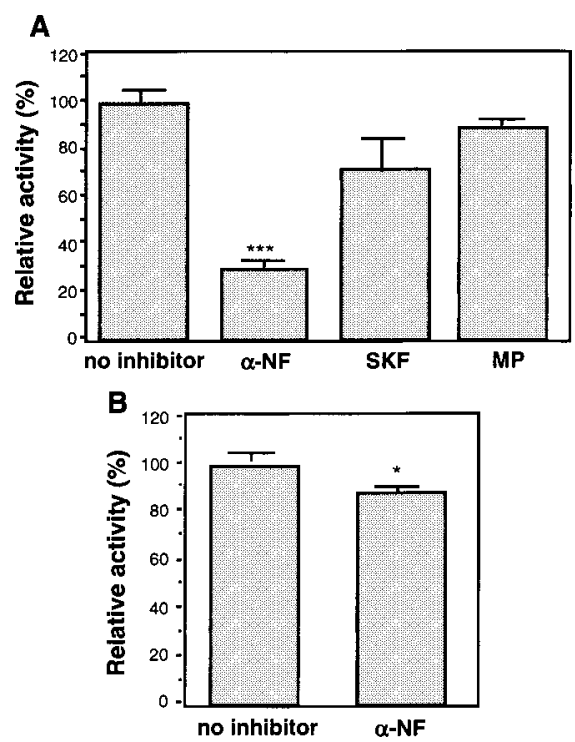

Fig. 1. Effects of Cytochrome P450 Inhibitors on the Activity of 3-Hydroxybenzo(a)pyrene UDP-Glucuronosyltransferase in Liver Microsomes from 3-Methylcholanthrene-Treated Rats

Microsomes were not permeabilized (A) or permeabilized (B) with $0.01 \%(\mathrm{w} / \mathrm{v})$ Brij58. The concentrations of $\alpha$-NF, SKF-525A (SKF) and metyrapone (MP) were 50, 100 and $100 \mu \mathrm{M}$, respectively. The control activities (without inhibitor) in experiment $\mathrm{A}$ and $\mathrm{B}$ were $5.34 \pm 0.19$ and $10.15 \pm 0.32 \mathrm{nmol} / \mathrm{min} / \mathrm{mg}$ protein, respectively. Each value represents the mean \pm S.E. of three assays. Significantly different $(* ; p<0.05$, and $* * *$; $p<0.005$ ) from no inhibitor group.

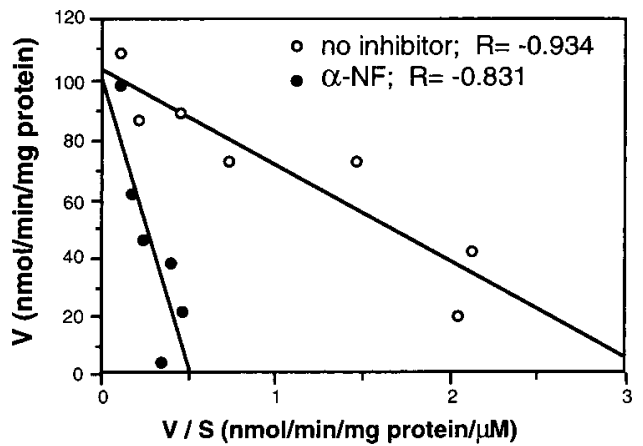

Fig. 2. Eadie-Hofstee Plots of 3-Hydroxybenzo( $a$ )pyrene Glucuronidation with or without $\alpha$-Naphthoflavone

Non-permeabilized microsomes from MC-treated rats were used as the enzyme sources. The concentration of $\alpha-\mathrm{NF}$ was $50 \mu \mathrm{M}$. Each plot represents the mean of duplicate assays.

Table 1. Kinetic Parameters of 3-Hydroxybenzo(a)pyrene Glucuronidation Catalyzed by Non-permeabilized Hepatic Microsomes from 3-Methylcholanthrene-Treated Rats

\begin{tabular}{llc}
\hline \hline Additive & $K_{\mathrm{m}}(\mu \mathrm{M})$ & $V_{\max }(\mathrm{nmol} / \mathrm{min} / \mathrm{mg}$ protein $)$ \\
\hline No inhibitor & $2.80 \pm 0.55$ & $10.3 \pm 0.5$ \\
$\alpha$-NF & $25.7 \pm 5.0$ & $11.7 \pm 0.9$ \\
\hline
\end{tabular}

The kinetics of 3-OH-B(a)P glucuronidation were examined with non-permeabilized microsomes in the presence and absence of $\alpha$-NF. It was found that $\alpha$-NF caused little change in the $V_{\max }$ of glucuronidation, but drastically increased the Michaelis-Menten constant $\left(K_{\mathrm{m}}\right)$ (Fig. 2, Table 1). This observation strongly suggests that $\alpha$-NF inhibits $3-\mathrm{OH}-\mathrm{B}(\mathrm{a}) \mathrm{P}$ glucuronidation by a competitive mechanism although it is a P450 inhibitor. $\alpha-\mathrm{NF}$ inhibited the $3-\mathrm{OH}-\mathrm{B}(\mathrm{a}) \mathrm{P}$ glucuronida- 
tion catalyzed by non-permeabilized microsomes in a concentration-dependent manner, but had hardly any effect on the activity with permeabilized microsomes (Fig. 3). The $\mathrm{IC}_{50}$ value of the inhibitory effect of $\alpha$-NF with non-permeabilized microsomes was approximately $10 \mu \mathrm{M}$. These results strongly suggest that $\alpha$-NF inhibits $3-\mathrm{OH}-\mathrm{B}(\mathrm{a}) \mathrm{P}$ UGT by a mechanism involving P450 inhibition but not by direct inhibition of UGT.

To examine the specificity of $\mathrm{P} 450$ ligands/inhibitors for UGT inhibition in more detail, other ligands for 3MC-inducible type $\mathrm{P} 450$ were examined to see if they affected UGT activity. The results showed that $\beta$-NF, B(a)P, ethoxyresorufin and MC significantly inhibited UGT activity when non-permeabilized microsomes were used, although the inhibitory effects were weaker than $\alpha$-NF (Table 2). As in the case of $\alpha$-NF, these compounds, except for ethoxyresorufin, exhibited inhibitory effects only on the non-permeabilized microsome-catalyzed activity. The other eight of the twelve compounds had no inhibitory effects.

We next examined the effects of substrates of CYP3A, a major constitutive $\mathrm{P} 450$, on the 3-OH-B(a)P glucuronidation by non-permeabilized microsomes from drug-untreated rats (Fig. 4). The CYP3A substrates examined were cyclosporine A, erythromycin, ketoconazole, nifedipine, chloramphenicol and testosterone. Although cyclosporine A exhibited a minor reduction in activity, the other compounds showed no signifi-

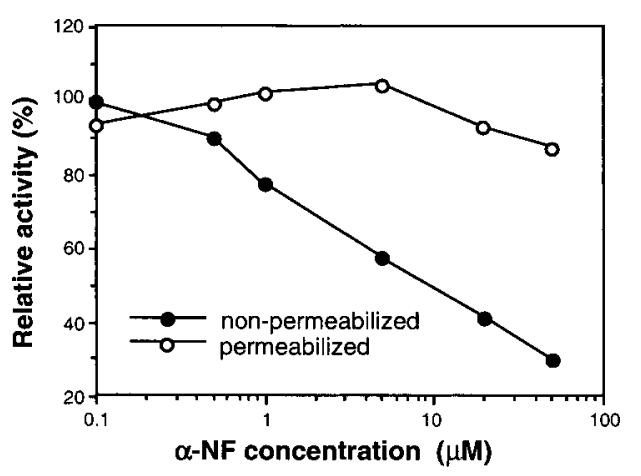

Fig. 3. Concentration-Dependence of the Inhibitory Effect of $\alpha$-Naphthoflavone on 3-Hydroxybenzo( $a$ )pyrene Glucuronidation Catalyzed by Hepatic Microsomes from 3-Methylcholanthrene-treated Rats

The activity was determined using non-permeabilized (closed symbol) and Brij58permeabilized (open symbol) microsomes. The values are the percentages relative to the control which was determined in the absence of $\alpha$-NF. Each plot represents the mean of duplicate assays. cant effect.

\section{DISCUSSION}

We hypothesized that $\mathrm{P} 450$ acts as a transporter of the substrate required by UGT. When non-permeabilized microsomes were used as the enzyme source, $\alpha$-NF markedly reduced 3-OH-B(a)P UGT activity. If $\alpha$-NF inhibits UGT directly, the inhibitory effect should be increased by increasing membrane permeability. This is because, due to so-called "latency", the lipid bilayer interferes with the access of inhibitor/substrate to UGT located within the ER. However, the experimental results reported here did not support this. In fact, the inhibitory effect of $\alpha-\mathrm{NF}$ was greatly reduced when used with detergent-permeabilized microsomes. This observation does not support the suggestion that inhibition is caused by a direct action of $\alpha$-NF with UGT. It is likely that $\alpha$-NF inhibition of 3-OH-B(a)P UGT is due to the effect on $\mathrm{P} 450$ and P450/UGT association is necessary for the inhibition. This phenomena is supported by our previous observation that CYP1A1 shows high affinity toward several UGT

Table 2. Effects of Cytcohrome P450 Ligands on UDP-Glucuronosyltransferase Activity Catalyzed by Hepatic Microsomes from 3-Methylcholanthrene-Treated Rats

\begin{tabular}{lcc}
\hline \hline \multirow{2}{*}{ Inhibitor } & \multicolumn{2}{c}{ Relative UGT activity ${ }^{a)}$} \\
\cline { 2 - 3 } & Non-permeabilized & Permeabilized \\
\hline No inhibitor & $100 \pm 3.63$ & $100 \pm 3.12$ \\
$\alpha$-Naphthoflavone & $30.57 \pm 2.67^{* *}$ & $88.26 \pm 2.01^{*}$ \\
$\beta$-Naphthoflavone & $82.65 \pm 1.33^{*}$ & $96.96 \pm 9.71$ \\
17 $\beta$-Estradiol & $99.19 \pm 1.01$ & $\mathrm{nd}$ \\
Testosterone & $104.75 \pm 4.62$ & $\mathrm{nd}$ \\
7-Ethoxycoumarin & $91.14 \pm 2.64$ & $\mathrm{nd}$ \\
7-Methoxycoumarin & $103.67 \pm 1.85$ & $\mathrm{nd}$ \\
7-Ethoxyresorufin & $93.51 \pm 2.06^{*}$ & $\mathrm{nd}$ \\
Benzo(a)pyrene & $70.45 \pm 3.69^{* *}$ & $93.79 \pm 8.96$ \\
3-Methylcholanthrene & $79.86 \pm 3.97^{* *}$ & $92.52 \pm 9.50$ \\
TCDD & $95.96 \pm 3.28$ & $\mathrm{nd}$ \\
Phenacetin & $98.01 \pm 2.64$ & $\mathrm{nd}$ \\
Acetanilide & $104.24 \pm 2.38$ & $\mathrm{nd}$ \\
\end{tabular}

a) Each value represents the mean \pm S.E. of three assays of the percentages for the no inhibitor $(=100)$. The concentrations $(\mu \mathrm{M})$ of inhibitors were: $\alpha$-NF, 50; $\beta$-NF, 50; $17 \beta$-estradiol, 100; testosterone, 100; 7-ethoxycoumarin, 100; 7-methoxycoumarin, $100 ; 7$-ethoxyresorufin, 50; $\mathrm{B}(\mathrm{a}) \mathrm{P}, 50 ; \mathrm{MC}, 50 ; 2,3,7,8$-tetrachlorodibenzo- $p$-dioxin (TCDD), 5; phenacetin, 100; and acetanilide, 200. Significantly different $(* ; p<0.05$, $* * ; p<0.005$ ) from the control (no inhibitor). nd; not determined.

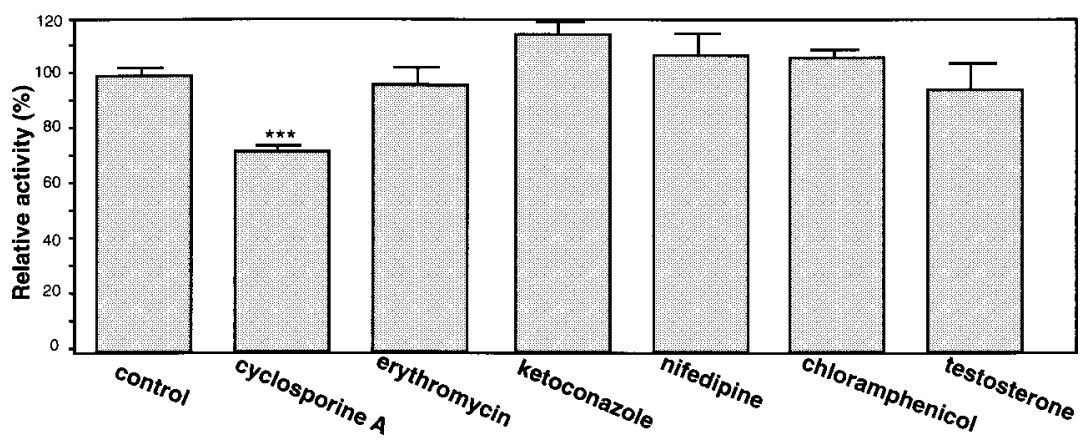

Fig. 4. Effect of CYP3A Substrates on UDP-Glucuronosyltransferase Activity

3-Hydroxybenzo $(a)$ pyrene $(5 \mu \mathrm{M})$ was incubated at $37^{\circ} \mathrm{C}$ for $5 \mathrm{~min}$ with rat liver microsomes $(50 \mu \mathrm{g}$ protein). Except for ketoconazole $(20 \mu \mathrm{M})$ and testosterone $(100 \mu \mathrm{M})$, the compounds were added to the reaction mixture at a concentration of $200 \mu \mathrm{M}$. Each value represents the mean \pm S.E. of three assays. Significantly different $(* * * ; p<0.005)$ from control group. Control activity without CYP3A substrates, $0.72 \pm 0.11 \mathrm{nmol} / \mathrm{min} / \mathrm{mg}$ protein. 
isoforms. ${ }^{17)}$ Further, Yoshitomi et al. ${ }^{28)}$ have reported that the activity of endogenous UGT in HepG2 cells varies following the expression of $\mathrm{P} 450$ transgenes. This observation may support our proposal for the cooperative interaction between P450 and UGT. Although we can not conclude which UGT isoform(s) are mainly involved in such interaction, UGT1A6 and 1A7 are highly inducible in liver by MC $^{29)}$ (UGT1A6 and $1 \mathrm{~A} 7$ are referred to as $\mathrm{A} 1$ and $\mathrm{A} 2$, respectively, in that report). While UGT1A6 has no ability to glucuronidate 3$\mathrm{OH}-\mathrm{B}(\mathrm{a}) \mathrm{P}^{26)}$ UGT1A7 exhibits activity toward this substrate as well as $\mathrm{B}(\mathrm{a}) \mathrm{P}-7,8$-dihydrodiol. ${ }^{27)}$ From these data, the MCmediated change in the glucuronidation of $\mathrm{B}(\mathrm{a}) \mathrm{P}$ metabolites is likely to be attributable to the altered expression of UGT1A7. Therefore, the UGT candidate present in MCtreated rat liver to which P450 (CYP1A1?) supplies/transports 3-OH-B(a)P seems to be UGT1A7.

Since $\alpha$-NF is rather specific for CYP1A $1,{ }^{30,31)}$ the inhibitory effect of this compound seems to be due to binding to CYP1A1. The observation that SKF-525A and metyrapone, less specific inhibitors of CYP1A, did not reduce $3 \mathrm{OH}-\mathrm{B}(\mathrm{a}) \mathrm{P}$ glucuronidation supports this view. Of the other CYP1A substrates examined, B(a)P, ethoxyresorufin and $\beta$-NF reduced UGT activity to some extent only when non-permeabilized microsomes were used, while ligands rather specific for CYP1A, such as TCDD and ethoxycoumarin, had no inhibitory effect (Table 2). The reason for the failure of these ligands to inhibit UGT remains unknown.

Interestingly, it has long been known that $\alpha$-NF stimulates the CYP3A-dependent metabolism of a number of exogenous and endogenous compounds. ${ }^{32-37)}$ Kinetic analyses on this stimulatory effect have demonstrated the presence of multiple binding sites for substrate and effecter $(\alpha-\mathrm{NF})$ within the catalytic cavity of the CYP3A enzyme. Based on these studies, $\alpha-\mathrm{NF}$ is assumed to bind to one of the multiple sites to cause changes in the steric and electronic environment within the catalytic cavity and also stimulate allosterically the oxidation of co-present drug which occurs at another site in the cavity. ${ }^{35,36,38-41)}$ Stimulation by effectors and the two binding-site model have also been demonstrated for other members of P450 including the CYP1A, 2B and 2C forms. ${ }^{39,42)}$ The same may be proposed for the P450-dependent activation of UGT, i.e. $\alpha$-NF specifically binds to an appropriate region of $\mathrm{P} 450$ to cause a change in conformation which allows association with UGT. The compounds other than $\alpha$-NF examined in this study appear to be poor ligands or had no ability to bind to the specific region. Thereby, the possibility that this compound exhibits UGT inhibition through interaction with CYP3A cannot be excluded, although this study detected no effect of CYP3A ligands on non-permeabilized microsome-catalyzed 3-OH-B(a)P glucuronidation except for cyclosporine A which had only a minor inhibitory effect (Fig. 4). Thus, it is likely the 3-OH$\mathrm{B}(\mathrm{a}) \mathrm{P}$ UGT inhibition detected in this study is mainly due to the $\alpha$-NF-CYP1A1 interaction. $\alpha$-NF had an inhibitory but not a stimulatory effect on CYP1A1-mediated metabolism of $\mathrm{B}(\mathrm{a}) \mathrm{P}^{43)}$ This observation does not support the view that both $\alpha-\mathrm{NF}$ and 3-OH-B(a)P can co-exist in the catalytic cavity of CYP1A1. It is, therefore, likely that $\alpha-\mathrm{NF}$ inhibits $3-\mathrm{OH}-$ B(a)P UGT by competitively blocking the entrance of 3-OH$\mathrm{B}(\mathrm{a}) \mathrm{P}$ into CYP1A1, a putative substrate transporter for UGT. Since CYP3A enzyme forms a complex with
CYP1 $A,{ }^{44)}$ an alternative possibility is that a cluster of these $\mathrm{P} 450 \mathrm{~s}$ is required for functioning as a putative transporter for UGT substrates.

The prediction of the metabolic profile is very important for the evaluation of the toxicity and bioavailability of newly synthesized drugs. The present study suggests P450-assisted UGT function may be important to evaluate drug metabolism. To obtain more accurate predictions about drug metabolism in vivo, more complex expression systems such as simultaneous expression of P450 and UGT in mammalian cells, are needed.

Acknowledgements This work was supported in part by a Grant-in-Aid for Scientific Research (B) (research No. 14370765) from the Japan Society for the Promotion of Science. We are very grateful to Dr. Nadao Kinoshita for providing authentic 3-hydroxybenzo( $a$ )pyrene glucuronide.

\section{REFERENCES}

1) Dutton G. J., "Glucuronidation of Drugs and Other Compounds," CRC Press, Boca Raton, 1980.

2) Meech R., Mackenzie P. I., Clin. Exp. Pharmacol. Physiol., 24, 907915 (1997).

3) Mackenzie P. I., Owens I. S., Burchell B., Bock K. W., Bairoch A., Bélanger A., Fournel-Gigleux S., Green M., Hum D. W., Iyanagi T., Lancet D., Louisot P., Magdalou J., Roy Chowdhury J., Ritter J. K., Schachter H., Tephly T. R., Tipton K. F., Nebert D. W., Pharmacogenetics, 7, 255-269 (1997).

4) Tukey R. H., Strassburg C. P., Ann. Rev. Pharmacol. Toxicol., 40, 581-616 (2000)

5) Aono S., Adachi Y., Uyama E., Yamada Y., Keino H., Nanno T., Koiwai O., Sato H., Lancet, 345, 958-959 (1995).

6) Meech R., Mackenzie P. I., J. Biol. Chem., 272, 26913-26917 (1997).

7) Ghosh S. S., Sappal B. S., Kalpana G. V., Lee S. W., Roy Chowdhury J., Roy Chowdhury N., J. Biol. Chem., 276, 42108-42115 (2001).

8) Ishii Y., Miyoshi A., Watanabe R., Tsuruda K., Tsuda M., YamaguchiNagamatsu Y., Yoshisue K., Tanaka M., Maji D., Ohgiya S., Oguri K., Mol. Pharmacol., 60, 1040-1048 (2001).

9) Shepherd S. R. P., Baird S. J., Hallinan T., Biochem. J., 259, 617-620 (1989).

10) Jansen P. L. M., Mulder G. J., Burchell B., Bock K. W., Hepatology, 15, 532-544 (1992).

11) Bock K. W., Lilienblum W., Biochem. Pharmacol., 28, 695-700 (1979).

12) Ikushiro S., Emi Y., Iyanagi T., Biochemistry, 36, 7154-7161 (1997).

13) Sakaguchi M., Mihara K., Sato R., EMBO J., 6, 2425-2431 (1987).

14) Sato T., Sakaguchi M., Mihara K., Omura T., EMBO J., 9, 2391—2397 (1990).

15) Shimozawa O., Sakaguchi M., Ogawa H., Harada N., Mihara K., Omura T., J. Biol. Chem., 268, 21399-21402 (1993).

16) Ahn T., Guengerich F. P., Yun C.-H., Biochemistry, 37, 12860-12866 (1998).

17) Taura K., Yamada H., Hagino Y., Ishii Y., Mori M., Oguri K., Biochem. Biophys. Res. Commun., 273, 1048-1052 (2000).

18) Taura K., Yamada H., Naito E., Ariyoshi N., Mori M., Oguri K., Arch. Biochem. Biophys., 402, 275-280 (2002).

19) Shou M., Korzekwa K. R., Crespi C. L., Gonzalez F. J., Gelboin H. V., Mol. Carcinogenesis, 10, 159-168 (1994).

20) Bauer E., Guo Z., Ueng Y.-F., Bell L. C., Zeldin D., Guengerich F. P., Chem. Res. Toxicol., 8, 136-142 (1995).

21) Mori M., Kinoshita N., Memoirs of Kyushu University School of Health Sciences (Fukuoka), 2, 27-34 (1975).

22) Kinoshita N., Gelboin H. V., Science, 199, 307-309 (1978).

23) Yamada H., Fujisaki H., Kaneko H., Ishii Y., Hamaguchi T., Oguri K., Biochem. Pharmacol., 45, 1783-1789 (1993).

24) Miller G. L., Anal. Chem., 31, 964 (1959).

25) Lowry O. H., Rosebrough N. J., Farr A. L., Randall R. J., J. Biol. Chem., 193, 265-275 (1951).

26) Mackenzie P. I., Rodbourn L., Iyanagi T., Cancer Res., 53, 1529 
$1533(1993)$

27) Grove A. D., Kessler F. K., Metz R. P., Ritter J. K., J. Biol. Chem., 272, 1621-1627 (1997)

28) Yoshitomi S., Ikemoto K., Takahashi J., Miki H., Namba M., Asahi S., Toxicology in Vitro, 15, 245-256 (2001).

29) Emi Y., Ikushiro S., Iyanagi T., J. Biochem. (Tokyo), 117, 392-399 (1995).

30) Murray M., Reidy G. F., Pharmacological Rev., 42, 85-101 (1990)

31) Halpert J. R., Guengerich F. P., Bend J. R., Correia M. A., Toxicol. Appl. Pharmacol., 125, 163-175 (1994).

32) Huang M. T., Johnson E. F., Muller-Eberhard U., Koop D. R., Coon M. J., Conney A. H., J. Biol. Chem., 256, 10897-10901 (1981).

33) Raucy J. L., Johnson E. F., Mol. Pharmacol., 27, 296-301 (1985).

34) Imaoka S., Imai Y., Shimada T., Funae Y., Biochemistry, 31, 60636069 (1992).

35) Shou M., Grogan J., Mancewicz J. A., Krausz K. W., Gonzalez F. J., Gelboin H. V., Korzekwa K. R., Biochemistry, 33, 6450-6455 (1994).

36) Ueng Y.-F., Kuwabara T., Chun Y.-J., Guengerich F. P., Biochemistry,
36, 370-381 (1997).

37) Harlow G. R., Halpert J. R., J. Biol. Chem., 272, 5396-5402 (1997).

38) Harlow G. R., Halpert J. R., Proc. Natl. Acad. Sci. U.S.A., 95, 66366641 (1998).

39) Korzekwa K. R., Krishnamachary N., Shou M., Ogai A., Parise R. A., Rettie A. E., Gonzalez F. J., Tracy, T. S., Biochemistry, 37, 41374147 (1998).

40) Hosea N. A., Miller G. P., Guengerich F. P., Biochemistry, 39, 59295939 (2000).

41) Shou M., Dai R., Cui D., Korzekwa K. R., Baillie T. A., Rushmore T. H., J. Biol. Chem., 276, 2256-2262 (2001).

42) Inouye K., Mizokawa T., Saito A., Tonomura B., Ohkawa H., Biochim. Biophys. Acta, 1481, 265-272 (2000).

43) Koley A., Buters J. T. M., Robinson R. C., Markowitz A., Friedman F. K., J. Biol. Chem., 272, 3149-3152 (1997).

44) Yamazaki H., Gillam E. M. J., Dong M.-S., Johnson W. W., Guengerich F. P., Shimada T., Arch. Biochem. Biophys., 342, 329-337 (1997). 